\title{
Investigation of the preservice teachers' science-pseudoscience distinction and epistemological beliefs
}

\author{
Nagihan Tanık Önal ${ }^{1}$ and Aslı Saylan Kırmızıgül ${ }^{2}$ \\ ${ }^{1}$ Niğde Ömer Halisdemir University, Faculty of Education, Turkey (ORCID: 0000-0002-5926-521X) \\ ${ }^{2}$ Erciyes University, Faculty of Education, Turkey (ORCID: 0000-0001-5678-8050)
}

\begin{abstract}
This study aims to investigate preservice teachers' science-pseudoscience distinctions, epistemological beliefs, and to explore the relationship between these two parameters. To this end, a correlational research design has been employed. The study was conducted with the participation of 182 preservice science and preschool teachers, with the data being collected through the Science-Pseudoscience Distinction Scale and Epistemological Beliefs Questionnaire using descriptive statistics, multiple regression analyses, and correlation analyses. The results reveal the participants to have sophisticated epistemological beliefs and the ability to distinguish between science and pseudoscience, as well as a positive medium-level correlation between these two variables. Moreover, when comparing results through the variables of gender, department, and whether or not teachers follow scientific publications or broadcasts, these variables have been found to not predict participants' levels of science-pseudoscience distinction or epistemological beliefs. The preservice teachers' levels of science-pseudoscience distinction were found to vary significantly only based on grade level and favoring of senior preservice teachers. In more specific analyses, the preservice science teachers' epistemological beliefs were found to be more developed than preservice preschool teachers, with epistemological beliefs to be more developed as grade level increases. In light of these findings, lessons are recommended to be enhanced with activities designed to improve epistemological beliefs and the ability to distinguish between science and pseudoscience.
\end{abstract}

Keywords: Preservice teachers; Epistemological belief; Distinction between science and pseudoscience

Article History: Submitted 13 February 2021; Revised 16 June 2021; Published online 10 July 2021

\section{Introduction}

Teachers develop beliefs about their teaching, their students' learning, and many issues related to themselves (Kılınç et al., 2017). These beliefs are powerful variables that can directly affect their behaviors and the learning/teaching process. Pajares (1992) stated beliefs to be effective in teachers' idea-production, judgment, and decision-making processes. All differences such as teachers using different teaching methods in their lessons or establishing different communication styles with their students despite having received similar training and following the same curriculum are actually due to differences in beliefs. For example, science teachers who believe in

Address of Corresponding Author

Aslı Saylan Kırmızıgül, PhD, Department of Mathematics and Science Education, Faculty of Education, Erciyes University, 38280, Kayseri, Turkey.

$\triangle$ aslisaylan@erciyes.edu.tr

How to cite: Tanık-Önal, N. \& Saylan-Kırmızıgül, A. (2021). Investigation of the preservice teachers' science-pseudoscience distinction and epistemological beliefs. Journal of Pedagogical Research, 5(3), 55-67. https://doi.org/10.33902/JPR.2021370582 
the certainty of scientific knowledge, the existence of a single scientific method, and the objectivity of scientists are known to intensively perform teacher-centered teaching through monologic discourses (Lederman, 1992).

When examining the nature of beliefs, teacher beliefs are seen to constitute a system (Fives \& Buehl, 2012). These beliefs in this system are interconnected and work in cooperation. Among these beliefs, epistemological and pedagogical beliefs develop over a long period of time, have a central position, and are difficult to change (Fives \& Buehl, 2012; Kılınç et al., 2017). Epistemological beliefs are central because they directly affect how an individual will learn or how a teacher will teach. Accordingly, epistemological beliefs can be said to have a uniquely important place in teachers' belief systems.

Epistemological beliefs are briefly defined as beliefs about the nature of knowledge (Schraw \& Olafson, 2002). According to Schommer (1990), epistemological beliefs should include the nature of knowledge and the nature of knowing and learning; these beliefs also include the following different independent dimensions: the source of knowledge, certainty of knowledge, organization of knowledge, control of learning, and speed of learning. According to Conley et al. (2004), epistemological beliefs include four dimensions: absoluteness of knowledge, development of knowledge, source of knowledge, and justification of knowledge. Among these, belief in the absoluteness of knowledge ranges from perception of scientific knowledge as true or false to the reflection of knowledge onto more than one different perspective. The belief in development of knowledge ranges from the acceptance of scientific knowledge as a static and immutable object to the acceptance that scientific thought and knowledge change over time based on new evidence. The belief in source of knowledge extends from viewing the source of knowledge as external authorities such as scientists and teachers to the individual as the creator of knowledge. Lastly, the dimension of justification of knowledge refers to how phenomena are seen, from being discovered through scientific investigations such as experiments/observations to understanding that knowledge emerges as a result of reasoning, thinking, and multiple experiments and observations. Individuals' epistemological beliefs range from naive to sophisticated (Hofer, 2008). Individuals with sophisticated epistemological beliefs believe that knowledge can be contextually evaluated as true or false; that the accuracy or inaccuracy of knowledge can be tested through hypothesis; that knowledge has a complex structure; that knowledge is shaped by the logic, data, and evidence individuals have; that the ability to learn can be developed; and that effort must occur for learning to happen. Considering all these explanations, strengthening scientific literacy by supporting epistemological beliefs is important in societies and education systems that aim to train scientifically literate individuals. In this regard, Murcia (2007) claimed that, in order to meet the needs of the science and technology developing in the 21st century and to train students as scientifically literate with a good conceptual understanding, education and training should be viewed from the perspective of epistemological beliefs.

Another characteristic that scientifically literate individuals are expected to have is that they can distinguish scientific knowledge from non-scientific knowledge that is claimed to be scientific. Claims with no scientific basis but that are presented as scientific, especially in written, visual, and audio media as well as social media environments, cause information pollution. These inaccuracies, known as pseudoscience, are beliefs and practices based on religious beliefs that do not go through the stages of scientific method and are only assumptions and personal explanations not supported by scientific research (Kirman-Çetinkaya et al., 2013). Pseudoscience here should be noted to be different from other non-scientific teachings because in pseudoscience, although scientific arguments are used in regard to the claim being made, these claims do not contain the standards required by science. In other words, the parties put forward their opinions with the claim of being scientific, but these claims are not systematic information emerging from a scientific methodology and have no chance of being confirmed either experimentally or theoretically (Swanson, 2016). When pseudoscientific claims are put forward as if they are scientific claims, society has difficulty to distinguishing between science and pseudoscience (Tseng et al., 2014). 
Studies have revealed a considerable number of people in the society to believe in pseudoscientific claims such as astrology, aliens, and lucky numbers (Moore, 2005). In this case, individuals who are able to make the distinction between science and pseudoscience are clearly needed in order to build a society consisting of scientifically literate individuals. In order to distinguish between science and pseudoscience, one must accurately know the characteristics of scientific knowledge, which is a product of scientific activities. This shows the importance of individuals having sophisticated epistemological beliefs. From this point of view, a relationship can be thought to exist between individuals' epistemological beliefs and their distinctions between science and pseudoscience. In this context, studies are seen to have focused on epistemological beliefs (Angeli \& Valanides, 2012; Kılıç \& Demirbağ, 2020; Soleimani, 2020; Vecaldo, 2020); the distinction between science and pseudoscience (Ayvac1 \& Bağ, 2016; Mirtz, 2007; Jupe \& Denault, 2019; Öztuna-Kaplan, 2014); the relationships among scientific epistemic beliefs, science teaching beliefs, and science-specific pedagogical content knowledge (Wu et al., 2021); the effect of epistemological beliefs on learning strategies (Liang et al., 2010; Schommer, 1990); conceptions of learning-teaching (Saeed et al., 2014; Tsai et al., 2011); academic performance (Chen \& Pajares, 2010; Topcu \& Y1lmazTuzun, 2009; Vecaldo, 2017); the use of the acquired knowledge in daily life (Evcim, 2010); argumentation skills (Oh \& Jonassen, 2007); the motivation of learning science (Chen \& Pajares, 2010); and self-efficacy (Kapucu \& Bahçivan, 2015; Tsai et al., 2011). However, no study is found in the literature to have focused on determining the predictors of epistemological belief or sciencepseudoscience distinction or to have tested the relationship between them. Therefore, the present research is considered helpful in filling this gap in the literature.

In order to train individuals with sophisticated epistemological beliefs and the ability to distinguish between science and pseudoscience, teachers are firstly expected to have these qualities. In this regard, this study investigates preservice teachers' epistemological beliefs and science-pseudoscience distinction, the predictors of these two parameters, and the relationship between these two variables. This study will identify in light of the findings the current state of preservice teachers what interventions to make to help them overcome their deficiencies if any, and what decision and suggestions can be made for Turkey's teacher-training policies. Selecting preservice teachers to be participants from among preservice science and preschool teachers is also important because science teachers play a very important role in the creation of a scientifically literate society. Individuals' understanding of science and development of their epistemological beliefs are known to start taking shape at an early age (Hofer, 2008). In addition, early ages are a critical period for developing the skills of research, analysis, and argumentative reasoning (Hofer \& Pintrich, 2002). Issues such as scientific knowledge, sources of knowledge, and access to knowledge should be addressed starting with the first stages of education. Regarding this point, science activities carried out in preschool education institutions play a big role as the first stage of formal education. Therefore, future preschool teachers, as well as science teachers, are expected to have advanced epistemological beliefs, to be equipped to distinguish between science and pseudoscience, and to transfer these to their students. A teacher who is not scientifically literate cannot be expected to train scientifically literate students. In addition, preschool children are quickly affected by teachers' thinking. For this reason, preschool teachers' science education is very important. Pseudoscience can be combated by having a strong science education in early childhood (Kallery, 2001). When considering all these issues, this study aims to investigate preservice science and preschool teachers' science-pseudoscience distinction, epistemological beliefs, and relationship between these two variables. Preservice teachers' science-pseudoscience distinction and epistemological beliefs may be affected by various personal factors such as gender, department, and status regarding following scientific publications or broadcast. At this point, Tsai (2000) emphasized psychometric factors such as preservice teachers' scientific epistemological beliefs and science teaching beliefs to be able to change over time with respect to culture. Therefore, considering personal factors has been recommended when examining these 
psychometric factors ( $\mathrm{Wu}$ et al., 2021). To this end, the study seeks to address the following questions:

i) What are preservice science teachers' and preschool teachers' levels of science-pseudoscience distinction?

ii) What are preservice science teachers' and preschool teachers' epistemological beliefs?

iii) Do preservice science teachers' and preschool teachers' gender, department, and status regarding following scientific publications/broadcasts predict their levels of sciencepseudoscience distinction?

iv) Do preservice science teachers' and preschool teachers' gender, department, and status regarding following scientific publications/broadcasts predict their epistemological beliefs?

v) Does a relationship exist between preservice science teachers' and preschool teachers' sciencepseudoscience distinction and epistemological beliefs?

\section{Method}

\subsection{Research Design}

Because the research aims to explore the relationship between preservice preschool teachers' and science teachers' levels of epistemological beliefs and science-pseudoscience distinction, the study uses the correlational design, which investigates the relationships that may exist between two or more variables as well as their implications for cause and effect (Fraenkel et al., 2012).

\subsection{Participants}

This study uses the convenience sampling, with 182 freshman, sophomore, junior, and senior year preservice teachers (154 females, 28 males; 72 preservice teachers, 110 preschool teachers) from two universities located in Turkey participating in the study.

\subsection{Data Collection Tools}

\subsubsection{Science-pseudoscience distinction scale}

The Science-Pseudoscience Distinction Scale (SPDS) was developed by Oothoudt (2008) and translated and validated to Turkish by Kirman-Cetinkaya et al. (2013). The original scale has 32 items and three sub-dimensions, whereas the Turkish version has 23 five-point Likert-type items and the four sub-dimensions of (1) pseudoscience, (2) scientific method, (3) science-pseudoscience distinction, and (4) pseudoscientific beliefs. The present research has found Cronbach's alpha of reliability for SPDS to be .70 .

\subsubsection{Epistemological beliefs questionnaire}

The Epistemological Beliefs Questionnaire (EBQ) was developed by Conley et al. (2004) to assess preservice teachers' epistemological beliefs. The questionnaire was translated and validated into Turkish by Ozkan (2008). The original version of EBQ has 26 items and four dimensions (i.e., source, justification, certainty, development). However, the Turkish version of EBQ has three subdimensions (i.e., source/certainty of knowledge, development of knowledge, and justification of knowledge) with a total of 24 five-point Likert-type items. Cronbach's alpha of reliability for EBQ has been calculated as 0.87 .

Data was collected in the 2020 spring semester. Data collection was carried out online due to the COVID-19 epidemic. The necessary permissions were obtained from the two universities. All participants were informed about the research aim, their right to leave the research at any time; all the rules pertaining to Turkey's Higher Education Institutions Scientific Research and Publication Ethics Directive have been followed. In the research, the participants signed the consent form involving detailed information about the voluntary and confidential nature of participation. Therefore, the principle of voluntary participation has been taken into consideration and the students' identities kept confidential. The same procedure was followed in collecting data at each university to ensure consistency in the data collection procedures. 


\subsection{Data Analysis}

The Statistical Package for Social Sciences (SPSS 26) was used to analyze the data. Firstly, descriptive statistics were analyzed to assess preservice teachers' epistemological beliefs and distinction between science and pseudoscience. Secondly, the assumptions were checked for multiple regression analysis that include homoscedasticity, independence of residuals, linearity, multicollinearity, normality, and outliers. The tolerance values for each variable are not less than .1 , and VIF values are less than 10. Therefore, the assumption of multicollinearity is not violated, nor for the outlier assumption. No curvilinearity exists because the residuals have a roughly rectangular distribution with most of the scores concentrated in the center around zero. Hence, the homoscedasticity and linearity assumptions are satisfied. The assumption of independence of residuals is satisfied with Durbin Watson values being between 1.5 and 2.5. Next, a multiple regression analysis was conducted in order to examine the extent to which gender, department, grade, and status regarding following scientific publications/broadcasts predict participants' epistemological beliefs and science-pseudoscience distinction. Lastly, a correlation analysis was conducted to determine the relationship between epistemological beliefs and sciencepseudoscience distinction.

\section{Results}

\subsection{Preservice Teachers' Science and Pseudoscience Distinction}

For SPDS, the highest total score that preservice teachers can get is 115 , and the lowest score is 23 . According to the results, preservice teachers' average score is 91.38 for SPDS. For each subdimension of SPDS, the highest score that a preservice teacher can get is 5 , and the lowest score is 1. Table 1 presents preservice teachers' levels regarding their ability to distinguish between science and pseudoscience based on the subscales from SPDS.

Table 1

Mean scores and standard deviations regarding the sub-dimensions of SPDS

\begin{tabular}{lll}
\hline Sub-dimension & $M$ & $S D$ \\
\hline Pseudoscience & 3.71 & 0.04 \\
Scientific method & 4.28 & 0.04 \\
Science/pseudoscience distinction & 4.03 & 0.04 \\
Pseudoscientific beliefs & 3.76 & 0.05 \\
\hline
\end{tabular}

As presented in Table 1, preservice teachers have stronger beliefs regarding scientific method $(M=4.28, S D=0.04)$ compared to the other three sub-dimensions. Namely, they have a more favorable understanding of the scientific method.

\subsection{PreService Teachers' Epistemological Beliefs}

For EBQ, the highest total score that preservice teachers can get is 120, and the lowest score is 24 . According to the results, preservice teachers' average score is 102.43 for EBQ. Table 2 presents the preservice teachers' epistemological beliefs based on EBQ's subscales.

Table 2

Mean scores and standard deviations regarding the sub-dimensions of EBQ

\begin{tabular}{lll}
\hline Sub-dimension & $M$ & $S D$ \\
\hline Source/certainty of knowledge & 4.12 & 0.05 \\
Development of knowledge & 4.33 & 0.04 \\
Justification of knowledge & 4.38 & 0.03 \\
\hline
\end{tabular}

\subsection{Preservice Teachers' Science/Pseudoscience Distinction in Terms of Different Variables}

A multiple regression analysis was conducted to investigate the extent to which gender, department, grade, and status regarding following scientific publications/broadcasts predict 
preservice teachers' science-pseudoscience distinction levels. The combination of predictor variables does not significantly relate to science-pseudoscience distinction scores $\left(F_{(5,138)}=1.44\right.$, $p>$.0005). The sample multiple correlation coefficient is .05, indicating that approximately $5 \%$ of the variance of science-pseudoscience distinction scores can be accounted for through the combination of the variables of gender, department, grade, and status regarding following scientific publications/broadcasts (see Table 3).

Table 3

Predictive power of independent variables on the distinction between science and pseudoscience

\begin{tabular}{lllll}
\hline Model & $d f$ & $F$ & $p$ & $R^{2}$ \\
\hline Regression & 5 & 1.442 & .21 & 0.05 \\
Residual & 138 & & & \\
Total & 143 & & & \\
\hline
\end{tabular}

The variable of grade significantly contributes statistically to the prediction of preservice teachers' science-pseudoscience distinction $(p<.05)$, while the other four variables do not significantly contribute $(p>.05$; see Table 4$)$.

Table 4

Significance values for independent variables regarding distinguishing between science and pseudoscience and epistemological beliefs

\begin{tabular}{lll}
\hline Variables & Science-pseudoscience distinction & Epistemological belief \\
\hline Department & .48 & .01 \\
Grade & .01 & .01 \\
Gender & .40 & .47 \\
Publication & .20 & .44 \\
Broadcast & .34 & .49 \\
\hline
\end{tabular}

According to the one-way ANOVA results, a significant difference is found between preservice teachers' science-pseudoscience distinction $(F=3.184 ; p<.05)$. In order to determine the direction of the difference, a post-hoc analysis was conducted. According to the Bonferroni test results, a difference is found between freshman $(M=88.51, S D=8.32)$ and seniors $(M=96.50, S D=2.12)$, and between freshman and juniors $(M=93.86, S D=8.10)$ in favor of seniors and juniors, respectively. Accordingly, as preservice teachers' grade level increases, they become more successful in distinguishing between science and pseudoscience.

As presented in Table 2, preservice teachers have more favorable beliefs in the justification of knowledge. According to the results, preservice teachers' average EBQ score $(M=4.28)$ is higher than their average SPDS score $(M=3.95)$.

\subsection{Preservice Teachers' Epistemological Beliefs in Terms of Different Variables}

A multiple regression analysis was conducted to investigate the extent to which gender, department, grade, and status regarding following scientific publications/broadcasts predict participants' epistemological beliefs. The combination of the predictor variables does not significantly relate to epistemological belief scores $\left(F_{(5,138)}=1.64, p>.0005\right)$. The sample multiple correlation coefficient is .06 , indicating that approximately $6 \%$ of the variance of epistemological belief scores can be accounted for by the combination of gender, department, grade, and status regarding following scientific publications/broadcasts (see Table 5).

More specifically, Table 4 shows the variables of department and grade to significantly contribute statistically to predicting preservice teachers' epistemological beliefs $(p<.05)$, while the other variables do not significantly contribute $(p>.05)$. 
Table 5

Predictive power of independent variables on epistemological beliefs

\begin{tabular}{llccc}
\hline Model & $d f$ & $F$ & $p$ & $R^{2}$ \\
\hline Regression & 5 & 1.442 & .21 & 0.06 \\
Residual & 138 & & & \\
Total & 143 & & & \\
\hline
\end{tabular}

According to the independent-samples t-test results, a significant difference has been found between preservice science teachers' epistemological beliefs $(M=103.14, S D=8.67)$ and those of preschool teachers $\left(M=99.26, S D=11.17 ; t_{(180)}=-2.33, p=.02\right)$ in favor of preservice science teachers. In other words, preservice science teachers have more sophisticated epistemological beliefs than preschool teachers. The one-way ANOVA results reveal a significant difference to be found among preservice teachers' epistemological beliefs in terms of grade $(F=2.481 ; p<.05)$. In order to determine the direction of the difference, a post-hoc analysis was conducted. According to the Bonferroni test results, a difference was found between freshman $(M=97.89, S D=10.73)$ and seniors $(M=113.00, S D=2.83)$ in favor of senior preservice teachers. The mean scores for sophomore $(M=102.01)$ and junior year preservice teachers $(M=102.15)$ are close to each other. According to these findings, as preservice teachers' grade level increases, their epistemological beliefs become more sophisticated.

\subsection{The Relationship between Preservice Teachers' Epistemological Beliefs and Science- Pseudoscience Distinction}

The related pairs, homoscedasticity, linearity, and outlier assumptions were checked before performing the Pearson product-moment correlation analysis. Once all the assumptions were satisfied, the relationship between epistemological beliefs and science-pseudoscience distinction was investigated using the Pearson product-moment correlation coefficient. Accordingly, a medium and positive correlation is found between the two variables $(r=.37, n=182, p<.0005)$, indicating that high levels of epistemological belief to be associated with high levels of science/pseudoscience distinction.

Pearson's correlation coefficients were also generated to measure relationships among the subdimensions of EBQ and SPDS (see Table 6).

Table 6

Intercorrelations Among the EBQ and SPDS Sub-Dimensions

\begin{tabular}{lccc}
\hline Sub-dimensions & $\begin{array}{l}\text { Source/certainty of } \\
\text { knowledge }\end{array}$ & $\begin{array}{l}\text { Development of } \\
\text { knowledge }\end{array}$ & $\begin{array}{c}\text { Justification of } \\
\text { knowledge }\end{array}$ \\
\hline Pseudoscience & .02 & $.15^{*}$ & .01 \\
Scientific method & .01 & $.36^{* *}$ & $.57^{* *}$ \\
Science/pseudoscience distinction & $.37^{* *}$ & $.34^{* *}$ & $.30^{* *}$ \\
Pseudoscientific beliefs & .00 & $.15^{*}$ & .12 \\
\hline
\end{tabular}

According to the results, a strong positive correlation is found between the sub-dimensions of scientific method and justification of knowledge $(r=.57)$. Moreover, medium positive correlations exist between the sub-dimensions of scientific method and development of knowledge $(r=.36)$ and between the sub-dimensions of science/pseudoscience distinction and the three sub-dimensions of the EBQ. Lastly, small positive correlations have been found between the sub-dimensions of pseudoscience and development of knowledge $(r=.15)$, and between the sub-dimensions of pseudoscientific beliefs and development of knowledge $(r=.15)$.

\section{Discussion and Conclusion}

This paper examined preservice teachers' science-pseudoscience distinction and their epistemological beliefs. The results showed that preservice teachers recognize scientific 
knowledge. However, many studies have revealed preservice classroom (Ayvacı \& Bağ, 2016; Şenler \& İrven, 2016), chemistry (Ağlarcı \& Kabapınar, 2016), and preschool (Kallery, 2001; Turgut et al., 2016) teachers to be unable to distinguish between science and pseudoscience. When examining the scores preservice teachers received on the sub-dimensions, preservice teachers' conception of scientific method was found to be stronger than the other three dimensions, as Şenler and İrven (2016) conluded. This may result from the courses preservice teachers take during their undergraduate education (e.g., scientific research methods, science teaching). In addition, some studies are found in the literature to have examined the pseudoscience beliefs of future teachers (Aarnio \& Lindeman, 2005; Großschedl et al., 2014; Losh \& Nzewke, 2011) and university students (Impey et al., 2012; Sugarman et al., 2011).

Another result from the study is that preservice teachers' epistemological beliefs are sophisticated. Parallel to this result, Murat (2018) found preservice science teachers to generally have sophisticated epistemological beliefs except for the dimension of knowledge being single and absolute. İçen's (2012) study found preservice social studies teachers' epistemological beliefs to be sophisticated in general, although they do have some traditional aspects. Similarly, Vecaldo (2017) and Aytaç (2020) claimed preservice teachers to have sophisticated epistemological beliefs. However, other studies have revealed participants to have a traditional level of epistemological development (Saeed et al., 2014). These results indicate epistemological beliefs to have a complex structure that is influenced by personal factors, individuals' social environment, and the culture they belong to. In this regard, Chan and Elliott (2000) found Chinese students to have stronger beliefs in certainty of knowledge and expert knowledge than American students, and explained this with respect to the element authority has in Asian culture.

In this study, participants received the highest score for the dimension of belief of justification of knowledge and the lowest score from the dimension of source/certainty of knowledge. This situation can be considered as proof of the lack of interdependence for the dimensions of epistemological belief, as Schommer-Aikins (2004) also has argued. Parallel to this, Şenler and İrven (2016) revealed preservice classroom teachers to have sophisticated beliefs in the dimension of justification of knowledge. When examining other studies, effort-based learning has been found to be the most sophisticated dimension (Aytaç, 2020; Lee et al., 2013).

The variables of gender, department, and status regarding following scientific publications/broadcasts did not significantly predict participants' levels of science-pseudoscience distinction in the current study. Moreover, the fact that grade level is the only factor to have a significant effect on preservice teachers' science-pseudoscience distinction supports the previous argument that undergraduate education has a significant effect on the development of preservice teachers' ability to distinguish between science and pseudoscience. Simiilar to this study, other studies are found to have shown the science-pseudoscience distinction to not be related to gender (Kirman-Çetinkaya \& Laçin-Şimşek, 2012; Lundström, 2007; Mirtz, 2007). However, while this study found no significant difference between preservice science and preschool teachers' levels of science-pseudoscience distinction, Tseng et al. (2014) stated studying science to be a factor that improves the ability to distinguish between science and pseudoscience.

The combination of the variables of gender, department, and status regarding following scientific publications/broadcasts was found to not significantly correlate with participants' epistemological beliefs. Some studies in the literature have found epistemological beliefs to vary significantly based on gender (Lodewyk, 2007; Yılmaz-Tüzün \& Topçu, 2013), while other studies stated epistemological beliefs to not vary significantly based on gender (Conley et al., 2004; Kaya \& Ekici, 2017; Şenler \& İrven, 2016; Tümkaya, 2012). In the present study, participants' epistemological beliefs vary significantly based on department and grade level. This difference is in favor of preservice science teachers and senior preservice teachers. The differences in the courses preservice science teachers and preschool teachers take from their high school education onwards and the differences among their domains of mental development may cause this difference in epistemological beliefs. Parallel to this result, some studies have reported the 
epistemological beliefs of preservice teachers majoring in natural sciences to be more sophisticated than the epistemological beliefs of the preservice teachers majoring in social sciences (Kürşad, 2015; Taşkın, 2020). The courses preservice science teachers take in their third year such as nature of science, history of science, and science laboratory applications may contribute to the development of their epistemological beliefs. Senior preservice science teachers' epistemological beliefs may be more developed as a result. In this connection, Deryakulu (2006) stated that epistemological beliefs have a structure that can change over time and that the main factors influential on the development of individuals' epistemological beliefs are mental development, family structure, age, education level, and culture while gender and field of study may also have significant effects on epistemological beliefs. Similar to the results of the study, Biçer et al. (2013) found preservice teachers' epistemological beliefs to vary significantly based on grade level but not based on gender. As in the present study, the literature is seen to state that students with naive epistemological beliefs in lower grades may have sophisticated epistemological beliefs in upper grades, which can be explained through academic improvement (Baldwin \& Alsumait, 2013; Buehl \& Alexander, 2001; Hofer \& Pintrich, 1997). These results suggest that epistemological beliefs have a complex structure and affect many variables while also being affected by many variables (Murat, 2018). A similar situation is encountered when making a literature review on the nature of science related to epistemological beliefs and science-pseudoscience distinction, which are the subject of the present study. While in some studies, participants' views about the nature of science were found to correlate to variables such as age (Murcia \& Schibeci, 1999), gender, and grade level (Türkaslan, 2014), in other studies, their views on nature of science were found to be independent of these variables (Akerson et al., 2010).

Lastly, a medium and positive correlation was found between participants' epistemological beliefs and science-pseudoscience distinction. Preservice teachers with high levels of epistemological beliefs indicate that they also have high levels of science-pseudoscience distinction. A strong and positive correlation was found between the sub-dimensions of scientific method and justification of knowledge, whereas low and positive correlations were found between the sub-dimensions of pseudoscience and development of knowledge and between the subdimensions of pseudoscientific beliefs and development of knowledge. In light of these results, an increase in the scores on methodology knowledge about scientific method can be argued to lead to an increase in the scores on justification of knowledge. As stated before, epistemological beliefs have been addressed in two types of studies. While the first group of studies focused on how epistemological beliefs form, what they are affected by, and how they change based on certain factors, the second group of studies focused on the things epistemological beliefs affect and the factors to which they relate. This study has both attempted to determine the predictors of epistemological beliefs and to reveal these beliefs' relationship with individuals' sciencepseudoscience distinction. In this regard, the study can be claimed to be original and current.

In light of the results from the study, the following suggestions can be made:

The participants have been found to have sophisticated epistemological beliefs and to be competent enough to distinguish between science and pseudoscience. In this regard, a qualitative study can be conducted in the future that performs a detailed investigation of the points that enable participants to reach this level of competence and thus develop educational policies accordingly. Having such a study seek an answer to the question of whether formal education and informal learning affects epistemological development and the ability to distinguish between science and pseudoscience would be useful, as would eliciting participants' opinions about their formal education. Moreover, although preservice teachers were found to have developed their epistemological beliefs and ability to distinguish between science and pseudoscience, the ways these beliefs and ability can be developed more can be investigated in this regard. In this context, elective courses can be offered in the programs of education faculties, and the content of the suitable courses can also be epistemologically enhanced. In relation to the science-pseudoscience distinction, media is known to have a role in disseminating pseudoscientific claims. Within this 
context, these claims in media can be analyzed in the media literacy elective course of both science and preschool education programs to help preservice teachers distinguish scientific knowledge from non-scientific knowledge that claims to be scientific.

In the study, preservice teachers' epistemological beliefs and science-pseudoscience distinction were found to not be significantly correlated with the combination of predictor variables. The suggestion can be made to conduct research on larger sample sizes in order to investigate the effects from different variables. However, preservice teachers' epistemological beliefs and sciencepseudoscience distinctions were found to vary significantly based on the variable of grade level in more specific analyses. Therefore, courses that would support the development of preservice teachers in these areas could be offered at any grade level of undergraduate education, and their development through the grade levels can be examined with longitudinal studies. In the study, participants' epistemological beliefs were also found to vary significantly based on department in favor of preservice science teachers. This may indicate that adding both elective and required courses to the curriculum in the department of preschool teaching that supports preservice teachers' epistemological development may be useful. Science classes alone are not enough to build a scientifically literate society. Instruction in all courses can be given in this direction. Therefore, providing not only science teachers but all branch teachers with the competence to conduct this type of instruction is important. Thus, conducting a comprehensive study with the participation of preservice teachers from different branches is also recommended.

This study has found that participants' development of epistemological beliefs also leads to their development of distinguishing science from pseudoscience. In this regard, courses should be enriched with activities designed to support the development of epistemological beliefs and the ability to distinguish between science and pseudoscience.

This research is limited to the 182 preservice teachers' epistemological beliefs and ability to distinguish between science and pseudoscience. The number of participants can be increased by including different departments in addition to preservice science and preservice preschool teachers. Moreover, preservice teachers from different universities can be chosen. Therefore, having this research design be applied to another university is highly recommended for further research by considering these limitations.

\section{References}

Aarnio, K., \& Lindeman, M. (2005). Paranormal beliefs, education, and thinking styles. Personality and Individual Differences, 39(7), 1227-1236. https://doi.org/10.1016/j.paid.2005.04.009

Ağlarc1, O. \& Kabapınar, F. (2016). Developing prospective chemistry teachers' views of science and pseudoscience. Amasya Education Journal, 5(1), 248-286.

Akerson, V.L., Buzzelli, C.A., \& Donnelly, L.A. (2010). On the nature of teaching nature of science: Preservice early childhood teachers instruction in preschool and elementary settings. Journal of Research in Science Teaching, 47(2), 213-233. https:// doi.org/10.1002/tea.20323

Angeli, C., \& Valanides, N. (2012). Epistemological beliefs and ill-structured problem-solving in solo and paired contexts. Journal of Educational Technology \& Society, 15(1), 2-14.

Aytaç, A. (2020). The effect of pre-service teachers' epistemological beliefs and educational philosophy tendency on teaching and learning conceptions [Unpublished doctoral dissertation]. Balıkesir University, Turkey.

Ayvacı, H. Ş. \& Bağ, H. (2016). Investigating the views of primary school teacher candidates' for science pseudo-science distinction. Amasya Education Journal, 5(2), 539-566.

Baldwin, L., \& Alsumait, D. (2013). The impacts of academic levels and information science on epistemological beliefs of undergraduate students. In R. McBride \& M. Searson (Eds.), Proceedings of Society for Information Technology \& Teacher Education International Conference 2013 (pp. 4635-4642). Association for the Advancement of Computing in Education (AACE).

Biçer, B., Er, H., \& Özel, A. (2013). The relationship between the epistemological beliefs and educational philosophies of the teacher candidates adopted. Journal of Theory and Practice in Education, 9(3), 229-242. 
Buehl, M. M., \& Alexander, P. A. (2001). Beliefs about academic knowledge. Journal of Educational Psychology Review, 13(4), 353-382. https:// doi.org/10.1023/A:1011917914756

Chan, K-W., \& Elliott, R.G. (2000). Explorotary study of epistemological beliefs of Hong Kong teacher education students: Resolving conceptual and empirical issues. Asia-Pacific Journal of Teacher Education, 28(3), 225-234. https://doi.org/10.1080/713650691

Chen, J. A., \& Pajares, F. (2010). Implicit theories of ability of Grade 6 science students: Relation to epistemological beliefs and academic motivation and achievement in science. Contemporary Educational Psychology, 35(1), 75-87. https:// doi.org/10.1016/j.cedpsych.2009.10.003

Conley, A.M., Pintrich, P.R., Vekiri, I., \& Harrison, D. (2004). Changes in epistemological beliefs in elementary science students. Contemporary Educational Psychology, 29, 186-204. https:/ / doi.org/10.1016/j.cedpsych.2004.01.004

Kuzgun, Y. \& Deryakulu, D. (2006). Eğitimde bireysel farklılıklar [Individual differences in education]. Nobel Publications.

Evcim, İ. (2010). The relation between 8th grade primary school students? epistemological beliefs, science lesson acquisition, level of use of science in daily life and academic success [Unpublished master's thesis]. Marmara University, Turkey.

Fives, H., \& Buehl, M. (2012). Spring cleaning for the "messy" construct of teachers' beliefs: What are they? Which have been examined? What can they tell us? K.R. Harris, S. Graham, \& T. Urdan (Eds.), Apa Educational Psychology Handbook: Individual differences and cultural and contextual factors, (pp. 471-99). American Psychological Association.

Fraenkel, J. R., Wallen, N. E., \& Hyun, H. (2012). How to design and evaluate research in education. McGraw Hill.

Großschedl, J., Konnemann, C., \& Basel, N. (2014). Pre-service biology teachers' acceptance of evolutionary theory and their preference for its teaching. Evolution: Education and Outreach, 7(18). https://doi.org/10.1186/s12052-014-0018-z

Hofer, B.K. (2008). Personal epistemology and culture. In M. S. Khine (Ed.), Knowing, knowledge and beliefs epistemological studies across diverse cultures (pp. 3- 22). Springer Science.

Hofer, B.K., \& Pintrich, P. R. (1997). The development of epistemological theories: Beliefs about knowledge and knowing and their relation to learning. Review of Educational Research, 67(1), 88-140. https://doi.org/10.3102\%2F00346543067001088

Hofer, B.K., \& Pintrich, P. R. (2002). Personal epistemology: The psychology of beliefs about knowledge and knowing. Lawrence Erlbaum Associates.

Impey, C., Buxner, S., \& Antonellis, J. (2012). Non-scientific beliefs among undergraduate students. Astronomy Education Review, 11(1), 101-111. https:/ / doi.org/10.3847/AER2012016

İçen, M. (2012). The epistemologıc beliefs of social science teachers and the teaching strategies they apply in the class [Unpublished master's thesis]. Erzincan University, Turkey.

Jupe, L. M., \& Denault, V. (2019) Science or pseudoscience? A distinction that matters for police officers, lawyers and judges. Psychiatry, Psychology and Law, 26(5), 753-765. https://doi.org/10.1080/13218719.2019.1618755

Kallery, M. (2001). Early-years educators' attitudes to science and pseudo-science: The case of astronomy and astrology. European Journal of Teacher Education, 24(3), 329-342. https://doi.org/10.1080/02619760220128888

Kapucu, S., \& Bahçivan, E. (2015). High school students' scientific epistemological beliefs, self-efficacy in learning physics and attitudes toward physics: A structural equation model. Research in Science $\mathcal{E}$ Technological Education, 33(2), 252-267. https://doi.org/10.1080/02635143.2015.1039976

Kaya, E., \& Ekici, M. (2017) An analysis of social studies teachers' epistemological beliefs and teaching styles in terms of several variables. Elementary Education Online, 16(2), 782-813.

Kılıç, M., \& Demirbağ, M. (2020). Identification and comparison of epistemological belief profiles of gifted students and their parents. Istanbul Aydin University Journal of the Faculty of Education, 6(2), 151-173.

Kılınç, A., Demiral, Ü., \& Kartal, T. (2017). Resistance to dialogic discourse in SSI teaching: The effects of an argumentation-based workshop, teaching practicum, and induction on a preservice science teacher. Journal of Research in Science Teaching, 54(6), 764-789. https:// doi.org/10.1002/tea.21385

Kirman-Çetinkaya, E. \& Laçin Şimşek, C. (2012, June). Öğretmen adaylarmnn bilimsel yönteme ilişkin bilgi düzeyleri: Bilim-sözde bilim ayrm [Knowledge levels of pre-service teachers on scientific method: Sciencepseudoscience distinction]. The 10th National Science and Mathematics Education Congress, Nigde, Turkey.

Kirman-Çetinkaya, E., Laçin Şimşek, C., \& Çalışkan, H. (2013). The adaptation study of science and pseudoscience distinction. Trakya University Journal of Education, 3(2), 31-43. 
Kürşad, M.Ş. (2015). Investigation of relationship between attitude toward scientific research and epistemological belief. Bolu Abant Izzet Baysal University Journal of Faculty of Education, 15(2), 217-246.

Lederman, N.G. (1992). Students' and teachers' conceptions of the nature of science: A review of the research. Journal of Research in Science Teaching, 29(4), 331-359. https:/ / doi.org/10.1002/tea.3660290404

Lee, J.C., Zhang, Z., Song, H., \& Huang, X. (2013). Effects of epistemological and pedagogical beliefs on the instructional practices of teachers: A Chinese perspective. Australian Journal of Teacher Education, 38(12), 120-146. https://doi.org/10.14221/ajte.2013v38n12.3

Liang, J.C., Lee, M.H., \& Tsai, C.C. (2010). The relations between scientific epistemological beliefs and approaches to learning science among science-major undergraduates in Taiwan. Asia-Pacific Education Researcher, 19(1), 43-59.

Lodewyk, K.R. (2007). Relations among epistemological beliefs, academic achievement, and task performance in secondary school students. Educational Psychology, 27(3), 307- 327, https://doi.org/10.1080/01443410601104080.

Losh, S. C. \& Nzekwe, B. (2011). The influence of education major: How diverse preservice teachers view pseudoscience topics. Journal of Science Education and Technology, 20(5), 579-591. https://doi.org/10.1007/s10956-011-9297-0

Lundström, M. (2007, August). Students' beliefs in pseudoscience [Paper presentation]. ESERA conference, Malmö, Sweden.

Mirtz, T.A. (2007). The attitudes, beliefs, and knowledge of university students on health-related scientific and pseudoscientific concepts [Unpublished doctoral dissertation]. University of Kansas, USA.

Moore, D.W. (2005). Three in four Americans believe in paranormal. Gallup Poll News Service.

Murat, A. (2018). The effect of science teachers' thinking styles and epistemological beliefs on the methods and measurement tools used [Unpublished doctoral dissertation]. Firat University, Turkey.

Murcia, K. (2007). Science for the 21. Century: Teaching for scientific literacy in the primary classroom. Teaching Science, 53(2), 16-19.

Murcia, K., \& Schibeci, R. (1999). Primary student teachers' conceptions of the nature of science. International Journal of Science Education, 21(11), 1123-1140. https:// doi.org/10.1080/095006999290101

Oh, S., \& Jonassen, D.H. (2007). Scaffolding online argumentation during problem solving. Journal of Computer Assisted Learning, 23(2), 95-110. https:// doi.org/10.1111/j.1365-2729.2006.00206.x

Oothoudt, B. (2008). Development of an instrument to measure understanding of the nature of science as a process of inquiry in comparison to pseudoscience. [Unpublished master's thesis] California State University, USA.

Ozkan. S. (2008). Modeling elementary students, science achievement: the interrelationships among epistemological beliefs, learning approaches, and self-regulated learning strategies [Unpublished doctoral dissertation]. Middle East Technical University, Turkey.

Öztuna-Kaplan, A. (2014). Research on the pseudo-scientific beliefs of pre-service science teachers: A sample from astronomy-astrology. Journal of Baltic Science Education, 13(3), 381-393.

Pajares, M.F. (1992). Teachers' beliefs and educational research: Cleaning up a messy construct. Review of Educational Research, 62(3), 307-332. https:// doi.org/10.3102/00346543062003307

Saeed, K., Reza, Z., \& Momene, G. (2014). Pre-service english teachers' epistemological beliefs and their conceptions of teaching. International Journal of Research Studies in Psychology, 3(1), 3-12. https:// doi.org/10.5861/ijrsp.2013.398

Schraw, G., \& Olafson, L. (2002). Teachers' epistemological world views and educational practices. Issues in Education 8(2), 99-149. https:// doi.org/10.1891/194589503787383109

Schommer, M. (1990). Effects of beliefs about the nature of knowledge on comprehension. Journal of Educational Psychology, 82(3), 498-504. https://doi.org/ https://doi.org/10.1037/0022-0663.82.3.498

Schommer-Aikins, M. (2004). Explaining The Epistemological Belief System: Introducing the embedded systemic model and coordinated research approach. Educational Psychologist, 39, 19-29. https://doi.org/10.1207/s15326985ep3901_3

Soleimani, N. (2020). ELT teachers' epistemological beliefs and dominant teaching style: a mixed method research. Asian-Pacific Journal of Second and Foreign Language Education, 5(12), 1-20. https://doi.org/10.1186/s40862-020-00094-y

Sugarman, H., Impey, C., Buxner, S., \& Antonellis, J. (2011). Astrology beliefs among undergraduate students. Astronomy Education Review, 10(1), 10-21. https:// doi.org/10.3847/ AER2010040

Swanson, E. S. (2016). Science and society: Understanding scientific methodology, energy, climate, and sustainability. Springer. https://doi.org/10.1007/978-3-319-21987-5 
Şenler, B. \& İrven, Ö. (2016). Primary pre-service teachers' epistemological beliefs and pseudoscientific beliefs. Mersin University Journal of the Faculty of Education, 12(2), 659-671.

Taşkın, T. (2020). Examining science philosophy preferences and scientific epistemological beliefs of physics, chemistry and biology teachers regarding to several variables. Journal of Theory and Practice in Education, 16(1), 1-19. https://doi.org/10.17244/eku.648820

Topcu, M.S., \& Yllmaz-Tuzun, O. (2009). Elementary students' metacognition an epistemological beliefs considering science achievement, gender and socioeconomic status. Elementary Education Online, 8(3), 676693.

Tsai, C. C. (2000). Relationships between student scientific epistemological beliefs and perceptions of constructivist learning environments. Educational Research, 42(2), 193-205. https://doi.org/10.1080/001318800363836

Tsai, C.C., Ho, H.N.J., Liang, J.C., \& Lin, H.M. (2011). Scientific epistemic beliefs, conceptions of learning science and self-efficacy of learning science among high school students. Learning and Instruction, 21(6), 757-769. https:// doi.org/10.1016/j.learninstruc.2011.05.002

Tseng, Y. C., Tsai, C. Y., Hsieh, P. Y., Hung, J. F., \& Huang, T. C. (2014). The relationship between exposure to pseudoscientific television programmes and pseudoscientific beliefs among Taiwanese university students. International Journal of Science Education, 4(2), 107-122. https://doi.org/10.1080/21548455.2012.761366

Turgut, H., Eş, H., Bozkurt-Altan, E., \& Öztürk-Geren, N. (2016). Pre-service pre-school teachers' perceptions of science and pseudo-science. International Online Journal of Educational Sciences, 8(1), 150-169. http://dx.doi.org/10.15345/iojes.2016.01.013

Tümkaya, S. (2012). The investigation of the epistemological beliefs of university students according to gender, grade, fields of study, academic success and their learning styles. Educational Sciences: Theory $\mathcal{E}$ Practice, 12(1), 75-95.

Türkaslan, M. (2014). Classroom teachers 'Views toward the study of the nature of science [Unpublished master's thesis]. Zirve University, Turkey.

Vecaldo, R. T. (2017). Epistemological beliefs, academic performance and teaching competence of pre-service teachers. Asia Pacific Journal of Multidisciplinary Research, 5(2), 114-124.

Vecaldo, R.T. (2020). Dimensionality and predictive validity of Schommer epistemological questionnaire among Philippine pre-service teachers. International Journal of Instruction, 13(2), 767 - 782. https://doi.org/10.29333/iji.2020.13252a

Wu, D., Liao, T., Yang, W., \& Li, H. (2021). Exploring the relationships between scientific epistemic beliefs, science teaching beliefs and science-specific PCK among pre-service kindergarten teachers in China. Early Education and Development, 32(1), 82-97. https:// doi.org/10.1080/10409289.2020.1771971

Yılmaz-Tüzün, Ö., \& Topçu, M.S. (2013). Exploration of preservice science teachers' epistemological beliefs, world views, and self-efficacy considering gender and achievement. Elementary Education Online, 12(3), 659-673. 